\title{
POR QUE HAVERIA NO BRASIL UM SISTEMA DE REVISÃO JUDICIAL SUPERFORTE? A ANÁLISE DO CONTROLE DE CONSTITUCIONALIDADE E O PROTAGONISMO DO PODER JUDICIÁRIO
}

\author{
Ana Luiza Novais Cabral ${ }^{1}$ \\ Sidiney Duarte Ribeiro ${ }^{2}$
}

\section{RESUMO}

$\mathrm{O}$ artigo analisa os aspectos relativos ao modelo brasileiro de controle de constitucionalidade, sendo debatido o nítido protagonismo do STF. A pesquisa se pautou em aderir uma acepção mais delineada entre ambos os instrumentos. O debate se demonstra relevante em torno do judicial review e sua possível fragilidade frente à democracia a partir da perspectiva de Mark Tushnet. Desta forma, o sistema de controle de constitucionalidade no Brasil, demonstra-se como um poder de revisão judicial superforte, onde a tensão entre sua atribuição judicial de garantia da permanência das limitações constitucionais se eleva ao último grau.

Palavras-chaves: Controle de Constitucionalidade; Revisão Judicial; Supremo Tribunal Federal; Súmula Vinculante; Democracia.

\section{WHY WOULD THERE BE A SUPERFORT STRONG JUDICIAL REVIEW SYSTEM IN BRAZIL? ANALYSIS OF CONSTITUTIONALITY CONTROL AND THE PROTAGONISM OF JUDICIAL POWER}

\section{ABSTRACT}

The article analyzes aspects related to the Brazilian model of constitutionality control, debating the clear role of the Supreme Court. The research was based on adhering to a more defined meaning between both instruments. The debate proves to be relevant around the judicial review and its possible fragility in the face of democracy from the perspective of Mark Tushnet. In this way, the constitutionality control system in Brazil, demonstrates itself as a super strong judicial review power, where the tension between its judicial attribution to guarantee the permanence of constitutional limitations rises to the last degree.

\footnotetext{
${ }^{1}$ Advogada. Doutoranda em Direito Público na área Democracia, Constituição e Internacionalização e Linha de Pesquisa Constitucionalismo Democrático na Pontifícia Universidade Católica de Minas Gerais. Bolsista CAPES. Mestre em Direito Ambiental pela Escola Superior Dom Helder Câmara. Pós-graduada em Direito Tributário pela Faculdade Gama Filho. Pós-graduada em Direito Ambiental pela Faculdade Integrada AVM. Graduada em Direito pela Faculdade de Ciências Sociais Aplicadas Newton Paiva. Pesquisadora do Grupo de Pesquisa 'A possibilidade da defesa dos ambientes pelo Direito Penal' da Escola Superior Dom Helder Câmara - ESDHC e do Grupo de Pesquisa 'Teoria do Direito e Constitucionalismo' da Pontifícia Universidade Católica de Minas Gerais. Editora de Seção da Revista da Faculdade Mineira de Direito da PUC-Minas (Qualis A1). Currículo Lattes: <http://lattes.cnpq.br/2623437173992273>. ORCID <https://orcid.org/0000-0002-3051-2328>. Endereço Eletrônico: anamutum@adv.oabmg.org.br

${ }^{2}$ Advogado. Mestrando na área Democracia, Constituição e Internacionalização da Linha de Pesquisa O Processo na construção do Estado Democrático de Direito da Pontifícia Universidade Católica de Minas Gerais. Pósgraduação em Prática Forense pelo Centro Universitário Newton Paiva. Pós-graduação em Ciências Penais pela Pontifícia Universidade Católica de Minas Gerais. Graduado em Direito pela Universidade José do Rosário Vellano. Currículo Lattes: <http://lattes.cnpq.br/3844569392695746>. ORCID <https://orcid.org/0000-0001-80678222>. Endereço Eletrônico: sidiney.duarte@yahoo.com.br
} 
Key Words: Constitutionality Control; Judicial Review; Federal Court of Justice; Binding Summary; Democracy.

\section{INTRODUÇÃO}

Inicialmente, vale dizer que outros sistemas federativos, entre as mais variadas democracias antigas, viabilizaram aos seus tribunais de hierarquia superior, derrubar a legislação ou os atos administrativos das unidades da federação, estados e províncias, que sejam opostos ao texto constitucional vigente no país. Assim, a defesa do poder dos tribunais federais, na análise das demandas estatais a fim de manter o sistema federativo, demonstra-se simples e direta.

Contudo, a autoridade de um tribunal superior, ao aferir a inconstitucionalidade de uma norma que foi adequadamente promulgada pelos órgãos constitucionais, mostra-se controversa. Dessa forma, se uma norma for aprovada como dispõe o Poder Legislativo de um governo democrático, por que haveria os magistrados o poder de declará-la inconstitucional? Se fosse possível simplesmente captar as intenções e os dizeres da norma com termos constitucionais, ocorreria uma defesa mais eficiente pelo Poder Judiciário.

No entanto, em todos os casos relevantes e intensamente contestados, a plena defesa se demonstra inviável, pois os magistrados, ao interpretarem o texto constitucional, fazem valer sua própria acepção, preceitos e tendências. Desse modo, juristas americanos lutam há décadas para disponibilizar uma fundamentação satisfatória para o abrangente poder de revisão judicial, que tem sido desempenhado pelo Supremo Tribunal Federal. Assim, vale dizer que permanece a divergência de inserir um órgão "não eleito" ao poder de definir decisões políticas que denotam consequência imediata na vida e no bem-estar dos cidadãos.

A Constituição Federal de 1988 é um marco essencial ao aferir maior confiança no papel do Poder Judiciário. Assim, o presente artigo possui como objetivo a análise crítica dos aspectos inerentes ao modelo brasileiro de revisão judicial, que afere ao Supremo Tribunal Federal a competência para desempenhar tanto o controle concentrado, quanto o difuso de constitucionalidade. Dessa maneira, a fim de debater a desenvoltura daquele órgão e adotar o diálogo entre os Poderes relativos ao texto constitucional, optou-se por reestabelecer a 
conjuntura histórica das competências dispostas à Suprema Corte, desde sua elaboração pela Constituição de 1891, até seu atual papel de "guardião do texto constitucional", através da redação de 1988, que trouxe à baila o modelo concentrado de controle.

Baseando-se nas características do estudo, tem-se uma pesquisa bibliográfica, qualitativa e descritiva que foi utilizada para sustentar cientificamente os objetivos da pesquisa. Com uma didática de cunho exploratório, a pesquisa realiza o levantamento bibliográfico, buscando reunir as informações sobre o tema com o propósito de identificar os assuntos relevantes que deem sustentação aos argumentos elencados.

\section{NOÇÕES INTRODUTÓRIAS AO MODELO BRASILEIRO DE CONTROLE DE CONSTITUCIONALIDADE}

O modelo brasileiro de controle de constitucionalidade foi instaurado, inicialmente, na Constituição Republicana de 1891, que definiu no primeiro texto constitucional às competências do Supremo Tribunal Federal, instituído sob influência da Supreme Court of the United States, a fim de processar e julgar as demandas "dispostas contra o Governo da União ou Fazenda Nacional", pautadas em posições constitucionais e perante a Constituição e quando for questionada a validade de normas ou de atos governamentais face ao texto constitucional. Nessa perspectiva, originou-se um modelo difuso e posteriormente de controle das normas, similar ao controle desempenhado nas cortes americanas.

Assim, a inspiração pautada no direito estadunidense mostrou nítida também no princípio da separação de poderes, posto que o texto constitucional de 1891, em seu dispositivo 15, estabelecia que o Executivo, Legislativo e Judiciário eram harmônicos e independentes entre si. Empregando uma acepção de autocontenção, a mencionada Corte resistiria em desenvolver a revisão judicial e, desse modo, almejaria não interferir sobre as ações dos demais poderes. A mencionada autocontenção judicial, de maneira oposta ao ativismo judicial, revelou-se em três ações, dispostas até o ano de 1988 (BARROSO, 2010, p. 9).

Inicialmente, vale pontuar que a Corte não adotaria de modo direto as leis constitucionais às circunstâncias não dispostas expressamente em seu âmbito de incidência. Em segundo lugar, quando declarava a inconstitucionalidade de normas e atos, iria se utilizar de elementos hermenêuticos rigorosos e conservadores. Por último, omitia-se do debate relativo às políticas públicas. Assim, as decisões em seara constitucional seriam concebidas como 
indevidas intervenções do direito em âmbitos exclusivos da política, compreendendo a separação de poderes como uma mera distribuição de atribuições (SILVA, 2009, p. 215).

O marco inicial rumo ao modelo concentrado e abstrato foi aferido pelo texto constitucional de 1934, onde sua redação preveria instrumentos de intervenção da União sobre os Estados quando negligenciados os princípios constitucionais dispostos em seu artigo $7^{\circ}$, inc. I. Por essa razão, a declaração de inconstitucionalidade se originou com a premissa de afastar a intervenção federal, sendo determinada somente ao Procurador-Geral da República, limitando a eficácia de norma interventiva à declaração de sua constitucionalidade pelo Supremo que, de maneira inédita, tornaria competente para dispor a constitucionalidade de norma.

Nessa esteira, as lições de Gilmar Mendes, define que estivesse "vedado ao Poder Judiciário conhecer de questões exclusivamente políticas, pois a representação seria uma fórmula judicial de resolução de conflito que deslocaria a questão do político ao jurídico" (MENDES, 1990, p. 22). Assim, através da EC n $16 / 95$ seria inserido no texto constitucional de 1946 a representação de inconstitucionalidade.

Desse modo, confiada essencialmente ao Procurador-Geral da República, a representação em comento seria considerada apta parcialmente a estimular decisões do STF sobre a constitucionalidade de norma ou ato, no âmbito federal ou estadual. O êxito da referida emenda, no entanto, seria o de demarcar a tendência e instaurar o controle abstrato, assim, o alcance material da ação seria amplificado, respaldando não somente princípios sensíveis, como também direitos tidos como objetivos.

Posteriormente, a Constituição Federal de 1988 emergiu como marco histórico da redemocratização do Brasil, ampliando a titularidade e o arcabouço do direito de ação conferido ao STF. Em seu dispositivo 103, a redação trouxe sete novas figuras legitimadas ao ajuizamento de ação direta de inconstitucionalidade, ação que ocorreu a representação (BRASIL, 1988).

Também foram elaboradas a ação direta de inconstitucionalidade por omissão e o mandado de injunção, sendo ambos os mecanismos voltados para a solução de condutas omissivas do legislador que colocam em prova a efetividade de leis constitucionais. Por último, instaurou-se de maneira subsidiária, a arguição de descumprimento de preceito fundamental, constituída para reparar ou afastar lesão decorrente de ato estatal.

Assim, vale dizer que a última fase do processo de concentração do modelo brasileiro ganhou destaque no ano de 2004, mediante a aprovação da EC n 45/2004. Desse modo, criou- 
se o instituto da Súmula Vinculante, onde sua aprovação pelo STF seria, em tese, condicionada às continuadas decisões sobre matérias constitucionais. Por essa razão, uma vez aprovada, a referida súmula vincularia não somente o Judiciário, mas também a Administração Pública direta e indireta em todos os âmbitos federativos.

Dessa maneira, a aprovação, revisão ou o cancelamento poderiam ser apresentadas apenas pelos indivíduos dispostos no artigo 103 da CF/88. Em se tratando do controle difuso, vale dizer que a mencionada emenda condicionou a admissibilidade de recurso extraordinário mediante a apresentação de repercussão com o Supremo denotando a importância jurídica, social ou financeira do tema debatido. Corroborando ao estudo, os ensinamentos do autor Virgílio Afonso da Silva elucidam que:

\footnotetext{
Para os mais desatentos, a concentração do modelo brasileiro conduziu a um modelo europeu, corriqueiro e superficialmente caracterizado como repressivo e concentrado. É nessa simplificação que reside o erro em pensar que com o aumento dessa concentração também no Brasil, o Supremo Tribunal Federal estaria a um passo de se transformar em um tribunal constitucional por excelência. Bastaria a análise das características do modelo europeu que, frequentemente eram ignorados, para evidenciar a distância entre um "tribunal constitucional por excelência" e o Supremo Tribunal Federal (SILVA, 2009, p. 216).
}

Sendo assim, três são os pontos relevantes do processo decisório do Supremo Tribunal Federal, que demonstra ser o modelo brasileiro contemporâneo, desde o ano de 1891, considerado uma cópia, ora benfeita, ora malfeita, do modelo estadunidense. O STF não possui o poder de decidir como instituição, tendo em vista que seus julgamentos são compreendidos pelo resultado da soma do voto de cada ministro, sendo insignificante a fundamentação apresentada para que a Corte decida pela constitucionalidade ou inconstitucionalidade.

A atribuição aferida ao STF se demonstra superlativa, pois, além de Corte, desenvolve a competência de foro judicial especializado ao decidir criminalmente casos envolvendo os titulares dos mais elevados cargos da República, e de tribunal de recurso em última instância, ao ratificar ou não o controle difuso aferido por tribunais inferiores. Contudo, "a análise do texto constitucional não viabiliza a atribuição da competência ao STF de fiscalizar os atos do poder constituinte derivado" (SILVA, 2009, p. 218).

Desse modo, um modelo forte de jurisdição constitucional aduz às Cortes a tarefa de verificar a compatibilidade entre normas constitucionais e infraconstitucionais (TUSHNET, 2011, p. 325). Possui essas, o dever de recusá-las através de efeitos legais, na existência de 
desacordos justificados a respeito do que seria constitucional ou não. Nessas ocasiões, ao oposto do majoritariamente defendido, o constitucionalismo não determina a prevalência do entendimento do tribunal perante a fundamentação do Parlamento.

Nessa perspectiva, até mesmo os modelos fortes de controle possuem instrumentos de revisão hábeis a solucionar decisões judiciais errôneas, como o processo de emenda à Constituição que, como demonstrado, o STF estaria apto a julgar atos do poder constituinte de reforma, sendo possível taxar o modelo brasileiro como sendo superforte (MENDES, 2010, p. 217).

Portanto, o texto constitucional de 1988 trouxe ao Brasil novas ações constitucionais, amplificou a conjuntura material da revisão judicial e legitimou novos indivíduos. Consequência da referida novidade se demonstrou na intensificação da postura ativista da corte, sob premissa de ser "a última alternativa do indivíduo". Desse modo, o ativismo judicial não pode confundir com a judicialização da política, pois a conjuntura institucional oriunda da $\mathrm{CF} / 88$ denota ao STF a "última palavra em relação ao decisório formal, que apresentaria os elementos de deliberação e de decisão dispostos no texto constitucional” (MENDES, 2010, p. 217).

\section{A CONCEPÇÃO DO STRONG FORM JUDICIAL REVIEW AFERIDA POR MARK TUSHNET}

A inquietude vislumbrada entre o poder de revisão judicial e a democracia é reconhecida e consagrada pelo constitucionalista americano Mark Tushnet, que, em sua obra, Taking the Constitution Away from the Courts, se dispõe a verificar, entre outros temas, a supremacia do Poder Judiciário e o controle de constitucionalidade, aferindo, desse modo, um capítulo exclusivo à contestação do judicial review. Nessa acepção, o marco mais interessante de seu livro para os objetivos do presente estudo se encontra em outra obra, Weak Courts, Strong Rights: Judicial Review and Social Welfare Rights in Comparative Constitutional Law.

Os debates sobre a legitimidade da jurisdição constitucional transpassam pela verificação de distintos modelos organizados com base nas experiências democráticas vivenciadas pela sociedade. Nessa acepção, encontra-se a classificação entre forte e fraca, e a superação da premissa de que o controle de constitucionalidade seria restrito à mera anulação 
da norma por ação judicial de maneira a dar relevância ao possível diálogo entre o Poder Judiciário e Legislativo (TUSHNET, 2011).

Desse modo, a concepção de Tushnet pondera que a revisão constitucional considerada forte se destoa da fraca pela elevada ou reduzida tensão entre a jurisdição constitucional e o autogoverno, considerado democrático. Assim, no controle de constitucionalidade forte, para superar a decisão aferida pela Corte, seria essencial uma emenda ao texto constitucional ou uma modificação no entendimento do referido Tribunal, o que consistiria, de modo geral, que os julgadores se aposentassem ou viessem a óbito para serem substituídos. Por seu turno, o controle de constitucionalidade fraco baseia na acepção de existência de instrumentos para que a população se opusesse, de modo simplificado e efetivo, às decisões que compreenderem, justificadamente, equivocadas (TUSHNET, 2008).

Nesse contexto, o controle de constitucionalidade forte encontra intimamente ligado ao poder aferido a uma Suprema Corte de decretar a inconstitucionalidade de normas ou atos violadores ao texto constitucional, sem que ocorra a possibilidade de superação da decisão pelos outros poderes, exceto em hipótese de Emenda à Constituição Federal, o que ocorre de maneira excepcional. Assim, esse controle forte é composto pelos modelos norte-americano e uma elevada parcela de países da Europa.

Dessa maneira, o que distingue os mencionados modelos seria a simplicidade em debater e a superação legislativa da decisão assentada em sede de controle de constitucionalidade. Corroborando ao estudo, as seguintes pontuam que:

\begin{abstract}
Modelos como o canadense e o inglês (após a entrada em vigor do Human Rights Act) são modelos fracos de controle de constitucionalidade. No caso canadense, porque o legislador pode, após uma decisão judicial de inconstitucionalidade, promulgar novamente a lei declarada inconstitucional e imunizá-la temporariamente contra futuras decisões judiciais de inconstitucionalidade (e renovar, se quiser, essa "imunidade" a cada cinco anos). No caso inglês, as decisões de controle de constitucionalidade, instituído pelo Human Rights Act, de 1998, não vinculam totalmente o legislador, sendo apenas decisões de incompatibilidade, mas não de invalidade. Em ambos os casos, como se percebe, o legislador tem a possibilidade de reabrir o diálogo, se assim entender conveniente. Ou seja: ele pode aceitar a decisão do Judiciário, mas pode também superá-la. É essa possibilidade de superação que é chamada de "legislative override" (SILVA, 2009, p. 213).
\end{abstract}

Sendo assim, o referido autor, em consonância a esse critério de possibilidade de maior ou menor diálogo, afere que o controle constitucional brasileiro seria classificado como "superforte", uma vez que, além de possuir os elementos típicos dos modelos fortes, o país 
também possui um texto constitucional com um abrangente rol de disposições imutáveis, sendo identificadas nas denominadas cláusulas pétreas (TUSHNET, 2008).

No entanto, vale ressaltar que, a decisão aferida em sede de controle de constitucionalidade, mesmo concentrado, em solo brasileiro não interliga o Poder Legislativo. Dessa forma, se é correto que se apresentem diversos limites à superação da decisão do Tribunal, não é correto que esta só poderia ocorrer através de emenda ao texto constitucional em todos os casos. Assim, essa disputa de poder, inserida em qualquer modelo de revisão constitucional, é o que leva as críticas frente à tentativa de se estruturar a democraticidade da jurisdição constitucional através da ocorrência de diálogos.

Assim, os ensinamentos de Tushnet compreendem o sentido de que o Poder Legislativo sempre possuirá a palavra final na interpretação da Lei Maior, ainda que no modelo forte. Desse modo, o autor aduz que "se destaca como elemento central do caráter antidemocrático da revisão judicial forte a diminuição do espaço de diálogo essencial para a expressão da soberania popular" (TUSHNET, 2008, p. 34).

O referido autor se propõe a debater o conflito existente entre o processo democrático e a adequação aos limites impostos constitucionalmente. Nessa perspectiva, no desenvolvimento de seus estudos, são dispostas duas maneiras de controle para uma situação inadequada no tocante aos processos democráticos e limites constitucionais, apresentados no início do século XIX, quais sejam: a supremacia do parlamento e a judicial review.

Em sua obra intitulada Alternative Forms of Judicial Review, Tushnet verifica que, no fim do século XX, reestruturou-se o que ele compreende por weak-form systems of judicial review, ponderando que a revisão judicial foi elaborada em uma forma considerada fraca, mas que foi modificada ao longo dos séculos até que se chegasse à acepção na qual os sistemas de revisão judicial fraco tivessem que ser reinventados (TUSHNET, 2003).

No tocante ao sistema de supremacia parlamentar, Tushnet aduz que os partidos políticos que se enfrentavam em eleições consideradas plausivelmente justas compreendiam determinados limites sobre aqueles que estivessem fortuitamente no poder. Assim, os detentores do poder, oriundos das elites sociais, possuíam atribuições normativas relativas ao exercício do poder dentro de determinados limites (TUSHNET, 2003).

$\mathrm{O}$ autor ainda verifica que, os constrangimentos normativos sobre os detentores do poder reduziram no decorrer do século XX e que a democratização da política diminuiu a presença das comuns e tradicionais elites sociais em cargos de liderança, pelo que, segundo 
Tushnet, dentre as maiores democracias mundiais, restaram seriamente comprometidas com a supremacia do parlamento somente a Áustria e a Nova Zelândia (TUSHNET, 2008).

Desse modo, nas lições do referido autor, é importante elucidar que:

\begin{abstract}
The political developments I have sketched made judicial review more attractive. By mid-1960s or so, most designers of modern constitutional systems concluded that some form of judicial review is the best means of ensuring that policies inconsistent with the constitution will not be implemented. Yet, giving judges the power to enforce constitutional limitations can threaten democratic self-governance. The reason is that constitutional provisions are often written in rather general terms. The courts give those terms meaning in the course of deciding whether individual statutes are consistent or inconsistent with particular constitutional provisions. But as a rule, particular provisions can reasonably be given alternative interpretations. And sometimes a statute will be inconsistent with the provision when the provision is interpreted in one way, yet would be consistent with an alternative interpretation of the same provision (TUSHNET, 2008, p. 19). ${ }^{3}$
\end{abstract}

Nessa perspectiva, o autor afere que ao sistema judicial review como modo de controle das políticas realizadas pelos processos democráticos diante das limitações constitucionais, foi gerada precedência sobre a soberania parlamentar. Vale destacar que o aludido autor pondera que a judicial review se tornou nitidamente atraente mediante à democratização dos processos de natureza política (TUSHNET, 2008).

Assim, resta nítido que o poder aferido aos magistrados para respaldarem o respeito às limitações constitucionais pode afrontar o autogoverno democrático e, para o aludido autor, a justificativa se encontra no fato de os provimentos constitucionais serem determinados em termos gerais, isto é, sendo viabilizadas diversas interpretações. Desse modo, a depender da interpretação utilizada, um mesmo statute pode ser considerado ora constitucional, ora inconstitucional.

Desse modo, considerando que as Cortes e os órgãos do Poder Legislativo podem - e frequentemente o fazem - discordar do significado que deve ser empregado a determinado provimento de ordem constitucional e que ambas as interpretações podem ser justificáveis e

\footnotetext{
3 "Os desenvolvimentos políticos que descrevi tornaram a revisão judicial mais atraente. Em meados da década de 1960, a maioria dos projetistas de sistemas constitucionais modernos concluiu que alguma forma de revisão judicial é o melhor meio de garantir que políticas inconsistentes com a constituição não sejam implementadas. No entanto, dar aos juízes o poder de impor limitações constitucionais pode ameaçar a autogovernança democrática. A razão é que as disposições constitucionais são frequentemente escritas em termos bastante gerais. Os tribunais dão sentido a esses termos ao decidir se os estatutos individuais são consistentes ou inconsistentes com determinadas disposições constitucionais. Mas, como regra, disposições particulares podem razoavelmente receber interpretações alternativas. E, às vezes, um estatuto será inconsistente com a provisão quando essa for interpretada de uma maneira, mas seria consistente com uma interpretação alternativa da mesma provisão" (Tradução Livre).
} 
razoáveis. Assim, Tushnet elucida uma nova indagação que atinge essencialmente o que cerne da tensão verificada: Por que deveria prevalecer a interpretação razoável da Corte em detrimento da interpretação também razoável, apesar de em outra acepção, do Legislativo? (TUSHNET, 2008).

Diante de tal indagação, o autor explica que o sistema de revisão judicial americano faz predominar a interpretação razoável da Corte e, desse modo, verificou-se esse sistema como "strong-form review", uma vez que as interpretações proferidas pela Suprema Corte são definitivas, não estando submetidas às revisões.

Em sua obra Weak-form Judicial Review and "Core" Civil Liberties, o referido autor apresenta a acepção da relevância da palavra para alterar um sistema de revisão judicial forte. Dessa forma, pondera que a Corte do Chief Justice Rehnquist deixou como herança a intensa defesa da supremacia judicial relativa à interpretação constitucional. Assim, o Chief Justice Rehnquist foi importante defensor daquilo que o autor nomeia de strong-form judicial review, onde o poder finalístico e permanente (não aberto a revisões) é aferido às Cortes para interpretarem o texto constitucional (TUSHNET, 2008).

Em um sistema de revisão forte, ocorre uma tensão vislumbrada entre a função judicial de garantia da prevalência das limitações constitucionais e a democracia, assim, o autor em comento destaca que aos indivíduos resta pouco a fazer quando as Cortes interpretam o texto constitucional de maneira razoável, mas não em consonância a uma interpretação igualmente razoável, vislumbrada por uma maioria.

Nessa situação, vale destacar que restaria somente o recurso de emenda à Constituição ou a espera pela aposentadoria ou falecimento de magistrado e sua substituição por magistrados com uma visão mais equilibrada daquilo que de fato, para maioria, quis aferir o texto constitucional. Ademais, as interpretações apresentadas por qualquer maioria eventual na Suprema Corte não são as únicas consideradas razoáveis, uma vez que tais interpretações são comumente objeto de discordâncias dentro da própria corte, com posições conflitantes de indivíduos igualmente razoáveis (TUSHNET, 2008).

Portanto, para Tushnet, o presente fato deve ser tido como suficiente para expor que existe realmente uma tensão entre a revisão judicial forte e o sistema democrático. Assim, o sistema americano é considerado pelo autor como um nítido exemplo de um sistema de revisão judicial forte, justificando-se na supremacia das Cortes relativa à interpretação da Constituição (TUSHNET, 2008). 


\section{POR QUE HAVERIA NO BRASIL UM SISTEMA DE REVISÃO JUDICIAL SUPERFORTE?}

Os argumentos demonstrados no presente artigo confirmam que haveria, no Brasil, um sistema de revisão judicial onde a inquietação constante entre o monopólio interpretativo da Suprema Corte e o sistema democrático são elevados ao nível máximo a fim de permitir a caracterização do sistema brasileiro de controle de constitucionalidade como sendo um sistema superforte.

Desse modo, verificam-se duas fundamentações a favor da existência da revisão judicial superforte no Brasil. O primeiro argumento consiste na acepção de que, de maneira oposta ao controle de constitucionalidade americano, modelo considerado forte para Tushnet, o controle de constitucionalidade no Brasil é frequentemente caracterizado como misto ou híbrido, isto é, um controle baseado no controle difuso e concentrado. Assim, o referido modelo vem apresentando intensas tendências ao fortalecimento do controle abstrato-concentrado em prejuízo ao controle concreto-difuso (TUSHNET, 2008).

Por seu turno, o segundo argumento compreende a reflexão de que a súmula vinculante, elemento do arsenal de ferramentas fortalecedoras do controle abstratoconcentrado, consiste em uma deturpação do stare decisis, mesmo que se fundamente que o trajeto a ser seguido em prol do controle de constitucionalidade brasileiro seria uma convergência cada vez mais elevada de um sistema kelseniano de controle de constitucionalidade, pelo qual a figura do STF compreenderia uma real corte constitucional, e que o referido sistema seria de revisão judicial forte. Em consonância aos estudos desenvolvidos por Tushnet, a súmula vinculante se demonstra como um fator extra ao sistema apresentado, que denota unicamente um controle de constitucionalidade abstrato-concentrado. (TUSHNET, 2008).

Ainda vale dizer que é no controle difuso do sistema americano que se encontra uma larga possibilidade de ampliação democrática sendo justificada pelos espaços desarmônicos que o sistema viabiliza. Desse modo, verifica-se que a Suprema Corte foi planejada como a plena guardiã do texto constitucional e que outras ferramentas somadas ao poder de revisão judicial como, por exemplo, o stare decisis, o writ of certiorari de cunho discricionário, o sistema de 
indicação de magistrados (com exceção aos órgãos de setores federais), podem se desenvolver como verdadeiros "filtros democráticos" (TUSHNET, 2008).

Todavia, a tensão existente entre a revisão judicial americana e o sistema democrático se mostra muito distante do embate observado em solo brasileiro, sobretudo a partir do movimento de abrangência do controle concentrado e da autoridade do STF, principalmente perante a determinação de imposição de súmulas vinculantes relativas aos demais órgãos do Judiciário e da Administração Pública.

Dessa forma, em observância à conjuntura brasileira, nota-se uma nítida elevação da tensão entre o poder de revisão judicial e a democracia, sendo adicionadas às súmulas vinculantes, ao controle concentrado e ao efeito vinculante da Ação Direta de Inconstitucionalidade - ADI's, Ação Direta de Constitucionalidade - ADC's, Reclamações, Arguição de Descumprimento de Preceito Fundamental - ADPF, a redução da relevância do recurso extraordinário e de diversos instrumentos processuais infraconstitucionais uniformizadores como, por exemplo, a súmula impeditiva de recursos, o indeferimento liminar de petição inicial, o julgamento de recursos especiais repetitivos, a PEC 15/2011, dispondo que, o Recurso Extraordinário seja ação rescisória extraordinária e que o Recurso Especial seja ação rescisória especial, reduzindo ainda mais a relevância desses mecanismos de controle concretodifuso.

Vale ressaltar que tais mecanismos denotam intenso caráter centralizador, uma vez que estimulam a função de filtro aristocrático à democracia que o STF pode desenvolver. Dessa forma, o sistema brasileiro é consagrado como sendo superforte, quando comparado com o sistema americano. Nessa perspectiva, os ensinamentos de Abernathy compactuam que:

The United States has a unified Supreme Court that is competent to hear a variety of cases. Unlike Germany and some other nations, the USA has no specialized constitutional court. Therefore, the power exercised in Marbury would fall upon all federal courts, because even the lower federal courts have jurisdiction over cases arising under federal law. The power also belongs to state courts, because they have general jurisdiction. In this sense the United States has a decentralized system of constitutional adjudication (ABERNATHY, 2006, p. 150). ${ }^{4}$

\footnotetext{
${ }^{4}$ Os Estados Unidos têm uma Suprema Corte unificada que é competente para ouvir uma variedade de casos. Ao contrário da Alemanha e de algumas outras nações, os EUA não têm um tribunal constitucional especializado. Portanto, o poder exercido em Marbury recairia sobre todos os tribunais federais, porque mesmo os tribunais federais inferiores têm jurisdição sobre os casos decorrentes da lei federal. O poder também pertence aos tribunais estaduais, porque eles têm jurisdição geral. Nesse sentido, os Estados Unidos têm um sistema descentralizado de adjudicação constitucional (Tradução Livre).
} 
Como bem asseveram John Ferejohn e Pasquale Pasquino, pode-se verificar a posição institucional dos tribunais constitucionais através de duas concepções: nos regimes de supremacia parlamentar e nos regimes de tripartição de poderes, cunhadas através dos estudos de Montesquieu. Assim, os autores elucidam que entre essas duas concepções se observa uma variação de sistemas constitucionais nos quais elementos de ambos os regimes se mesclam. (FEREJOHN; PASQUINO, 2009, p. 52).

Pontuam, ainda, que os regimes jurídicos que aderem à divisão de poderes apresentam uma separação horizontal de poderes e possuem tendência a conferir a cada um destes, determinada função e autoridade constitucional.

O sistema norte-americano pode compreender, em relação à posição institucional do tribunal constitucional, empregado como um regime de separação de poderes pelo qual o Supremo somente pode desempenhar o controle de constitucionalidade das normas quando o debate for apresentado no seio de casos concretos e divergentes, isto é, que viabilizem o debate em qualquer outra corte. Desse modo, os ensinamentos de Ferejohn e Pasquino revelam que "a capacidade de se revisar a lei se encontra difusa no poder judiciário, ou seja, todos os tribunais devem interpretar a lei, constitucional ou infraconstitucional, para aplicá-la” (FEREJOHN; PASQUINO, 2009, p. 52).

Durante os anos de 1965 a 1988, ocorreu um notável fortalecimento do controle abstrato-concentrado no Brasil. A emenda $\mathrm{n}^{\circ}$ 16/1965 ao texto constitucional de 1945 instaurou, juntamente da representação interventiva, o controle abstrato de leis federais e estaduais, abrangendo a competência do Procurador-Geral da República de judicializar litígios políticos. Assim, ocorreu uma amplificação de possibilidades representativas com a finalidade de intervenção, isto é, para além dos princípios sensíveis.

Até a promulgação do texto constitucional de 1988, o singular entendimento da Suprema Corte no exercício de controle de constitucionalidade das leis, que detinha eficácia vinculante no tocante aos demais órgãos do Judiciário, era o condizente à inconstitucionalidade expressa em sede de controle abstrato-concentrado. Nessa conjuntura, seria apresentada eficácia erga omnes independentemente de manifestações do Senado. Todavia, a declaração de inconstitucionalidade em sede de controle concreto pela Suprema Corte, ao contrário, poderia dotar eficácia erga omnes apenas no caso de manifestação do Senado nessa acepção (FEREJOHN; PASQUINO, 2009, p. 52). 
Dessa forma, o texto constitucional de 1988 adotou o controle difuso praticamente na conjuntura das constituições passadas, isto é, sendo excluídos os casos que passaram a ser objeto de recurso especial para o STJ, originado em 1988. Assim, o constituinte de 1988 determinou que, no controle difuso, cabe ao STF conhecer a matéria em última instância através de recurso extraordinário, com fulcro no artigo 102, inciso III da CF/88.

Nessa esteira, Gilmar Mendes pondera, contudo que, o sistema brasileiro não acumula a um único tipo de ação ou de recurso à prerrogativa de proteção de direitos fundamentais. Assim, o referido autor fundamenta que "as ações constitucionais do habeas corpus, o habeas data, o mandado de segurança, o mandado de injunção, a ação civil pública e a ação popular" como elementos integradores do sistema brasileiro de controle difuso de constitucionalidade (MENDES, 2012, p. 03).

Vale ressaltar que o controle abstrato-concentrado se submeteu a relevantes mudanças através do texto constitucional de 1988, deixando de ser realizado através da representação pelo Procurador-Geral da República com a elaboração da ação direta de inconstitucionalidade ou ato normativo federal ou estadual, com fulcro no dispositivo 102, inciso I e, também, da arguição de descumprimento de preceito fundamental, embasada no mesmo dispositivo, parágrafo único (BRASIL, 1988).

Portanto, verifica-se no sistema de controle de constitucionalidade brasileiro contemporâneo, uma clara relevância do controle abstrato-concentrado sobre o concreto-difuso, ocorrendo, dessa forma, um elevado afastamento entre o sistema de controle de constitucionalidade atual e aquele inserido no Brasil no ano de 1890 nos ideais do judicial review norte-americano. Assim, aconteceu uma aproximação do sistema brasileiro no tocante ao sistema europeu de controle e da Suprema Corte em relação a um tribunal ou Corte constitucional onde sua função única se pauta na guarda do texto constitucional por meio do controle abstrato-concentrado de constitucionalidade.

\section{CONSIDERAÇÕES FINAIS}

Através da realização do presente estudo, verificou-se que a Constituição Federal de 1988 ampliou a conjuntura material da revisão judicial de maneira a legitimar novas figuras. Desse modo, o reflexo da mencionada novidade demonstrou através do impulsionamento à postura ativista da Suprema Corte sob o fundamento de ser a última alternativa do cidadão. No 
entanto, o ativismo judicial não pode ser confundido com a judicialização da política, uma vez que a estruturação institucional proveniente do texto constitucional de 1988 afere ao STF a última palavra no tocante ao decisório formal, que denotaria os aspectos de deliberação e de decisão elencados na $\mathrm{CF} / 88$.

Desse modo, o estudo identificou que o sistema de revisão forte, proposto nos estudos de Mark Tushnet, compreende uma tensão observada entre a função judicial de garantia da prevalência das limitações constitucionais e a democracia. Nessa conjuntura, o renomado autor evidenciou que aos indivíduos pouco resta a fazer quando as Cortes Supremas interpretam o texto constitucional de modo razoável, mas não em concordância a uma interpretação igualmente razoável, verificada por uma maioria.

Verificou-se também que, duas acepções foram cunhadas em favor da existência da revisão judicial superforte no sistema brasileiro, onde a primeira se compreende, de modo oposto ao controle de constitucionalidade verificado no direito norte-americano, estrutura considerado forte para Tushnet, onde o controle de constitucionalidade do Brasil vislumbra como misto ou híbrido, ou seja, consiste em um controle baseado no difuso e concentrado. Dessa forma, o mencionado modelo vem desempenhando fortes tendências no fortalecimento do controle abstrato em detrimento ao controle concreto-difuso.

E, por sua vez, a segunda acepção se caracteriza na compreensão de que a súmula vinculante, componente do arcabouço de mecanismos fortalecedores do controle abstratoconcentrado, baseia na deturpação do stare decisis. Nestes termos, ainda que se fundamente que o caminho a ser trilhado em prol do controle de constitucionalidade seria uma divergência cada vez mais latente de um sistema kelseniano de controle de constitucionalidade, pelo qual a Suprema Corte se revela como uma verdadeira Corte Constitucional, o mencionado se enquadra num sistema de revisão judicial forte.

Portanto, a tensão observada entre a revisão judicial americana e o sistema democrático se apresenta muito afastada da tensão obtida no Brasil, principalmente através do movimento de ampliação do controle concentrado e da competência da Suprema Corte, essencialmente mediante a determinação de imposição de súmulas vinculantes relacionadas aos demais órgãos do Poder Judiciário e da Administração Pública direta e indireta.

Dentro do contexto apresentado, cumpre salientar que o presente trabalho não obteve a pretensão de esgotar o assunto, mas sim tocar em aspectos relevantes da matéria, de modo a iniciar um debate e contribuir para a formação de uma consciência sobre o tema. 


\section{REFERÊNCIAS BIBLIOGRÁFICAS}

ABERNATHY, Charles. Law in the United States: American casebook series. Thompson west: 2006.

BARROSO, Luís Roberto. Constituição, democracia e supremacia judicial: direito e política no Brasil contemporâneo. Revista Jurídica da Presidência, Brasília, DF, v. 12. 2010.

BRASIL. Constituição da República Federativa do Brasil de 1988. Diário Oficial da União, Brasília, $\quad 5 \quad$ out. $1988 . \quad$ Disponível <http://www.planalto.gov.br/ccivil_03/constituicao/ConstituicaoCompilado.htm>. Acesso em: 28 nov. 2019.

FEREJOHN, John; PASQUINO, Pasquale. Tribunais Constitucionais como Instituições Deliberativas. In: BIGONHA, Antonio Carlos Alpino; Moreira, Luiz (org.). Limites do Controle de Constitucionalidade. Rio de Janeiro: Lúmen Júris, 2009.

MENDES, Gilmar. Controle de Constitucionalidade: aspectos jurídicos e políticos. São Paulo: Saraiva, 1990.

MENDES, Gilmar. O controle de constitucionalidade no Brasil. Disponível em:http://www.stf.jus.br/repositorio/cms/portalStfInternacional/portalStfAgenda_pt_br/anexo/ Con trole_de_Constitucionalidade_v_Port1.pdf. Acesso em 26 de nov. de 2019.

SILVA, Virgílio Afonso da. O STF e o controle de constitucionalidade: deliberação, diálogo e razão. Revista de Direito Administrativo, São Paulo, n. 250. 2009.

TUSHNET, Mark. Weak Courts, Strong Rights: Judicial Review and Social Welfare Rights in Comparative Constitutional Law. Princeton: Princeton University Press, 2008.

TUSHNET, Mark. Alternative Forms of Judicial Review. 2013. Disponível em: http://scholarship.law.georgetown.edu/facpub/259. Acesso em 28 nov. de 2019.

TUSHNET, Mark. The Rise of Weak-Form of Judicial Review. In: GINSBURG, Tom; DIXON, Rosalind (Ed.). Comparative Constitutional Law. Cheltenham and Northampton: Edward Elgar, 2011. 